\title{
Voltammetric Method Based on an Ion-Pairing Reaction for the Determination of Trace Amount of Iodide at Carbon-Paste Electrodes
}

\author{
Qiong He, Junjie FEI, and Shengshui Hu ${ }^{\dagger}$ \\ Department of Chemistry, Wuhan University, Wuhan, 430072, P. R. China
}

\begin{abstract}
Carbon-paste electrodes (CPEs) were studied to elucidate the cathodic stripping voltammetric determination of iodine. At an accumulation potential of $1.0 \mathrm{~V}(v s$. SCE), iodide was preconcentrated on CPEs via an ion-pairing reaction, followed by oxidation to iodine. Then a linear scan voltammogram was recorded after $10 \mathrm{~s}$ of quiescent time by a cathodic potential scan from $0.7 \mathrm{~V}$ to $0.1 \mathrm{~V}$ at a scan rate of $100 \mathrm{mV} \mathrm{s}^{-1}$. A cathodic peak current was obtained at about $0.38 \mathrm{~V}$. Various experiment parameters such as the acidity, chloride concentration, accumulation potential, accumulation time, concentration of cetyltrimethylammonium bromide $(\mathrm{CTAB})$ and scan rate, were optimized to analyze the iodide by employing linear-scan stripping voltammetry. Under the optimal conditions, calibration curves were obtained over a wide concentration range of the iodide ion from $8 \times 10^{-9} \mathrm{~mol} \mathrm{~L}^{-1}$ to $5 \times 10^{-6} \mathrm{~mol} \mathrm{~L}^{-1}$ with a detection limit of $2 \times 10^{-9} \mathrm{~mol}$ $\mathrm{L}^{-1}$ at an accumulation time of $3 \mathrm{~min}$. The effect of interfering species was evaluated and the procedure was applied to an iodide analysis in table salt, with good results.
\end{abstract}

(Received November 27, 2002; Accepted February 3, 2003)

\section{Introduction}

Iodine is an essential trace element for the human organism because iodine-containing hormones (triiodothyronine and thyroxine) produced in the thyroid gland play a very important role in mental development, growth, and basic metabolism. Numerous analytical methods have been proposed in the literature for the determination of different iodine species in aqueous solution. Samples containing higher concentrations of iodine can be analyzed by titrimetric and spectrophotometric methods,${ }^{1}$ while the detection of trace amounts requires more expensive and rather complicated instrumental techniques, ${ }^{2-6}$ such as gas or ion chromatography, inductively coupled plasma atomic emission spectroscopy or mass spectrometry (ICP-AES, ICP-MS), and neutron activation analysis. Most of these methods either require an extensive sample pretreatment, or involve a chemical transformation of iodide before detection to improve the sensitivity.

Electrochemical methods for the determination of iodine have been reported. Some of them utilize the formation of an insoluble products at the working electrode (e.g. $\mathrm{Hg}_{2} \mathrm{I}_{2}$ at a mercury electrode, ${ }^{7}$ or $\mathrm{AgI}$ at a silver electrode),${ }^{8}$ the formation of an uncharged adsorbed species at a platinum surface, ${ }^{9}$ or an ion-pairing with zephiramine at a glassy carbon electrode. ${ }^{10}$ Anodic ${ }^{11-14}$ or cathodic ${ }^{15}$ stripping voltammetry has been applied after the preconcentration of iodide or iodine onto carbon-paste electrodes or chemically modified carbon-paste electrodes (CPEs). A potentiometric stripping analysis at carbon-paste

$\doteqdot$ To whom correspondence should be addressed.

E-mail: sshu@whu.edu.cn

Q. H. present address: Department of Chemistry, Qujing Normal College, Yunnan 655000, P. R. China. electrode was also reported. ${ }^{16}$

Farsang ${ }^{17}$ studied the redox behavior of the $\mathrm{I}_{2} / \mathrm{I}^{-}$system using a CPE made with silicone oil. In his report, the redox system, $\mathrm{I}_{2} / \mathrm{I}^{-}$, was chemically reversible, but electrochemically irreversible, and the slow rate of polarization for the electrogenerated iodine species was attributed to its solubilization into the pasting liquid. Švancara ${ }^{15}$ demonstrated a synergistic effect of ion-pairing formation on the extractive preconcentration of iodide as iodine onto a carbon paste surface by using tricresyl phosphate as a pasting liquid. The major drawbacks of this method are its method accuracy and a relatively high detection limit.

The present investigation studied a new cathodic stripping voltammetric method for the determination of trace iodide at CPEs by using cetyltrimethylammonium bromide (CTAB) as an ionic associating agent. Iodide can be oxidized into molecular iodine on $\mathrm{CPE},{ }^{17}$ i.e. $\mathrm{I}_{3}^{-}$in an iodide medium or $\mathrm{I}_{2} \mathrm{Cl}^{-}$in a chloride medium. As a long-chain tetraalkyl ammonium salt, CTAB can be strongly adsorbed onto a carbon-paste electrode and form an ion-pair compound with some voluminous anions, such as $\mathrm{I}_{3}^{-}$and $\mathrm{I}_{2} \mathrm{Cl}^{-}$, the accumulation of iodide as iodine is therefore very effective, and significantly increased the sensitivity of the analysis. Compared with other methods reported in the literature, our procedure exhibits a much wider calibration range (nearly 3 orders of magnitude in concentration), a good reproducibility, and a lower detection limit.

\section{Experimental}

Reagents and samples

Stock solutions of iodide $\left(0.1 \mathrm{~mol} \mathrm{~L}^{-1}\right)$ were prepared from potassium iodide (analytical grade) by adding doubly distilled 


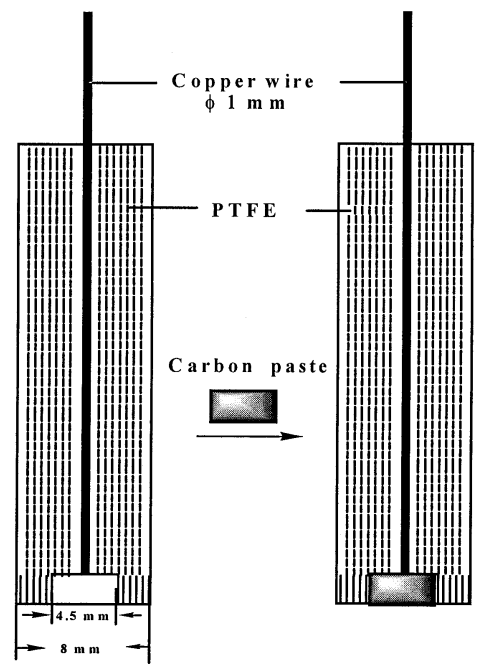

Fig. 1 Schematic drawing of the carbon-paste electrode.

water deaerated with nitrogen and kept in the dark. Diluted standard solutions $\left(1 \times 10^{-4} \mathrm{~mol} \mathrm{~L}^{-1}\right)$ were prepared freshly before use. Cetyltrimethylammonium bromide (CTAB) stock solutions were $1 \times 10^{-2} \mathrm{~mol} \mathrm{~L}^{-1}$. Graphite powder (spectral reagent; the average size of a graphite particle was about $\phi 10$ $\mu \mathrm{m})$ and paraffin oil were purchased from Shanghai Reagent Corporation (Shanghai, China). Real samples were prepared by dissolving $2 \mathrm{~g}$ of table salt in doubly distilled water, and then diluted to $100 \mathrm{~mL}$. All other chemicals were analytical-grade reagents and solutions were prepared from doubly distilled water.

\section{Preparation of carbon-paste electrodes}

Homogeneous carbon pastes were made by hand-mixing 100 mg of graphite powder and $20 \mu \mathrm{L}$ of paraffin oil. As illustrated in Fig. 1, the carbon paste was packed into the end of a homemade polytetrafluoroethylene (PTFE) cylindrical tube $(\phi$ $4.5 \mathrm{~mm}$ ). Electrical contact to the carbon paste was established via a thin copper wire passed through the PTFE. Fresh electrode surfaces were obtained by polishing on a weighing paper until they showed a smooth and shiny appearance. Activation of the renewed electrode surfaces was carried out by anodic scanning from $0.7 \mathrm{~V}$ ( $v s$. SCE) to $0.1 \mathrm{~V}$ after holding the electrode at $1.0 \mathrm{~V}$ for $1 \mathrm{~min}$ in a blank acidic chloride solution. After every measurement, the electrode surface needs to be mechanically regenerated by removing the outer layer of the carbon-paste electrode.

\section{Procedures}

All electrochemical measurements were carried out with a Model CHI830 electrochemical analyzer (CH Instrument Inc., USA) connected to a computer at room temperature. A conventional three-electrode cell was employed with a platinum wire as a counter electrode, a saturated calomel electrode (SCE) as a reference electrode and CPE as a working electrode. All potentials were quoted with respect to SCE. Cyclic voltammetry was firstly used to characterize the electrochemical behavior of iodine and iodide species at a freshly prepared electrode, and linear-scan voltammetry was then applied on the determination of iodide. A typical determination experiment included a two-step procedure: a preconcentration at $1.0 \mathrm{~V}$, followed by cathodic stripping voltammetric detection. A freshly prepared electrode was immersed for a given period of

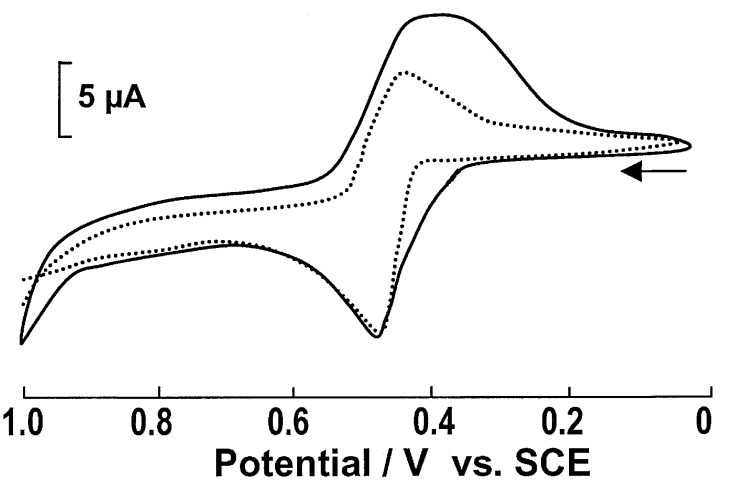

Fig. 2 Cyclic voltammograms of $5 \times 10^{-4} \mathrm{~mol} \mathrm{~L}^{-1} \mathrm{I}^{-}$in the absence of CTAB (dot line) and in the presence of CTAB (solid line) in 0.1 mol L ${ }^{-1} \mathrm{HCl}$ between 0 to $1.0 \mathrm{~V}$. Scan rate, $50 \mathrm{mV} \mathrm{s}^{-1}$.

time in a $10 \mathrm{~mL}$ electrolyte cell containing iodide, $0.1 \mathrm{~mol} \mathrm{~L}^{-1}$ $\mathrm{HCl}$ and $1 \times 10^{-4} \mathrm{~mol} \mathrm{~L}^{-1} \mathrm{CTAB}$ under constant stirring at 1.0 V. A linear scan voltammogram was then recorded after $10 \mathrm{~s}$ of quiescent time by a cathodic potential scan at a scan rate of 100 $\mathrm{mV} \mathrm{s}^{-1}$. The cathodic peak potential was obtained at about 0.38 V. The sample solution was measured by the standard addition method, by spiking a very small volume of relatively concentrated iodide standard solution, so that the dilution could be neglected in the calculation.

\section{Results and Discussion}

Voltammetric behavior of iodide and iodine at CPES

The electrochemical behavior of iodide $\left(5 \times 10^{-4} \mathrm{~mol} \mathrm{~L}^{-1}\right)$ was studied in an acidified chloride supporting electrolyte at paraffin oil-based CPEs by using cyclic voltammetry over a potential range from $0 \mathrm{~V}$ to $1.0 \mathrm{~V}$. In a positive scan, an oxidation peak was obtained at about $0.46 \mathrm{~V}$, corresponding to the oxidation of iodide to iodine, also, at a reversal scan a reduction peak of iodine which formed in the previous scan occurred at nearly $0.41 \mathrm{~V}$ (Fig. 2, dotted line). Both the oxidation and reduction peaks were well-defined and the separation of two peaks was about $50 \mathrm{mV}$, indicating that the quasireversible monoelectronic charge-transfer processes of $\mathrm{I}_{2} / \mathrm{I}^{-}$couple at the paraffin oil-based CPEs. Note that because these curves were recorded directly after immersing the electrodes into the solution, the peak currents were mainly due to solution-phase iodide and its oxidation product. When CTAB was added, we presumed that both iodide ions $\left(\mathrm{I}^{-}\right)$and iodine $\left(\mathrm{I}_{2} \mathrm{Cl}^{-}\right)$may partly form ion-pairs with $\mathrm{CTAB}$ cations, and are adsorbed on the electrode surface because of the strong affinity of lipophilic carbon paste for CTAB. This means that two forms of iodine or iodide contributed to the peak currents. The affinity of $\mathrm{I}_{2} \mathrm{Cl}^{-}$towards CTAB may be much stronger than $\mathrm{I}^{-}$towards it, and the observed split of the increased reduction response and only a small defomation of the oxidation response (not increased) have confirmed this presumation.

Accumulation and stripping voltammetric behavior of iodide at CPEs

Figure 3 illustrates the processes occurring at the surface of the CPE. After an accumulation of iodide at a positive potential in the presence of CTAB, a cathodic potential scan was carried out, and a well-defined reduction peak was observed at $0.38 \mathrm{~V}$ (Fig. 3a). Figure 3c demonstrates that the cathodic peak of 


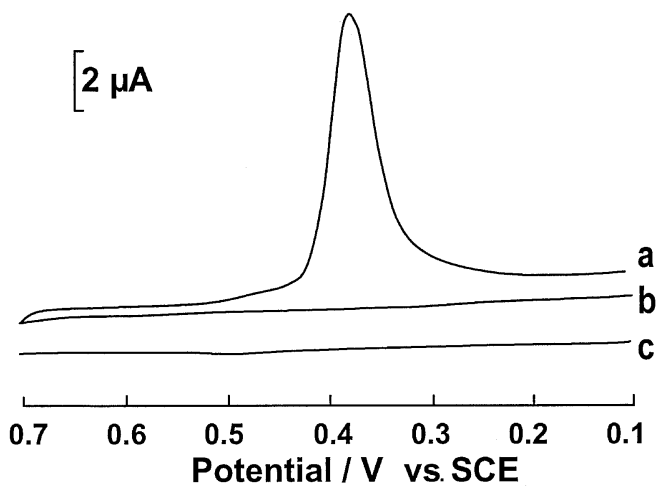

Fig. 3 Linear scan voltammograms at a carbon-paste electrode in $0.1 \mathrm{~mol} \mathrm{~L}-1 \mathrm{HCl}$ : (a) $1 \times 10^{-4} \mathrm{~mol} \mathrm{~L}^{-1} \mathrm{CTAB}+5 \times 10^{-7} \mathrm{~mol} \mathrm{~L}^{-1}$ iodide; (b) $1 \times 10^{-4} \mathrm{~mol} \mathrm{~L}^{-1} \mathrm{CTAB}$; (c) $5 \times 10^{-7} \mathrm{~mol} \mathrm{~L}^{-1}$ iodide; accumulation potential, $1.0 \mathrm{~V}$; accumulation time, $60 \mathrm{~s}$; scan rate, 100 $\mathrm{mV} \mathrm{s}^{-1}$.

iodine at the CPE disappeared in the absence of CTAB. The signals obtained in this way indicated that the iodine could not be adsorbed onto the electrode surface without CTAB. Another parallel experiment was carried out by immersing the CPE in an acidic solution containing iodine, and was accumulated without applying any potential. Approximately the same voltammogram as that in Fig. 3a (not shown) was obtained, which further confirmed the accumulation of CTAB to iodine. From the discussion presented above, we presumed the electrode processes as follows:

In acidic media, the molecule of CTAB was dissociated, and firstly adsorbed onto the electrode surface, and then formed ionpairs with iodide ions diffused to the electrode/solution interface, and accumulated them onto the electrode surface (reaction (1)):

$$
\mathrm{CTA}^{+}{ }_{\text {surf }}+\mathrm{I}^{-}{ }_{\text {sol }} \rightarrow\left[\mathrm{CTA}^{+}, \mathrm{I}^{-}\right]_{\text {surf }} \text {. }
$$

The index surf denotes the electrode surface and sol the bulk solution. Then, the iodide ions adsorbed on the electrode surface were oxidized to iodine owing to the applied positive potential:

$$
2\left[\mathrm{CTA}^{+}, \mathrm{I}^{-}\right]_{\text {surf }} \rightarrow 2\left[\mathrm{CTA}^{+}\right]_{\text {surf }}+\mathrm{I}_{2, \text { sol }}+2 \mathrm{e}^{-} .
$$

The released iodine could form aggregates with chloride ions:

$$
\mathrm{I}_{2, \text { sol }}+\mathrm{Cl}^{-}{ }_{\text {sol }} \rightarrow \mathrm{I}_{2} \mathrm{Cl}^{-}{ }_{\text {sol }} \text {. }
$$

The resulting species were voluminous anions, which were again immobilized at the electrode surface via the formation of ion-pairs with $\mathrm{CTAB}$ cations:

$$
\left[\mathrm{CTA}^{+}\right]_{\text {surf }}+\mathrm{I}_{2} \mathrm{Cl}^{-} \text {sol } \rightarrow\left[\mathrm{CTA}^{+}, \mathrm{I}_{2} \mathrm{Cl}^{-}\right]_{\text {surf. }}
$$

Finally, when a cathodic potential scan was applied, the adsorbed iodine was reduced to iodide (reaction (5)) at about $0.38 \mathrm{~V}$. Because of the difference in the affinity of iodide and iodine towards CTAB, only a small part of the iodide reduced was still adsorbed on the electrode surface,

$$
\left[\mathrm{CTA}^{+}, \mathrm{I}_{2} \mathrm{Cl}^{-}\right]_{\text {surf }}+2 \mathrm{e}^{-} \rightarrow \mathrm{I}^{-}{ }_{\text {sol }}+\mathrm{Cl}^{-}{ }_{\text {sol }}+\left[\mathrm{CTA}^{+}, \mathrm{I}^{-}\right]_{\text {surf }}
$$

The reduction peak potential of iodine shifted negatively from

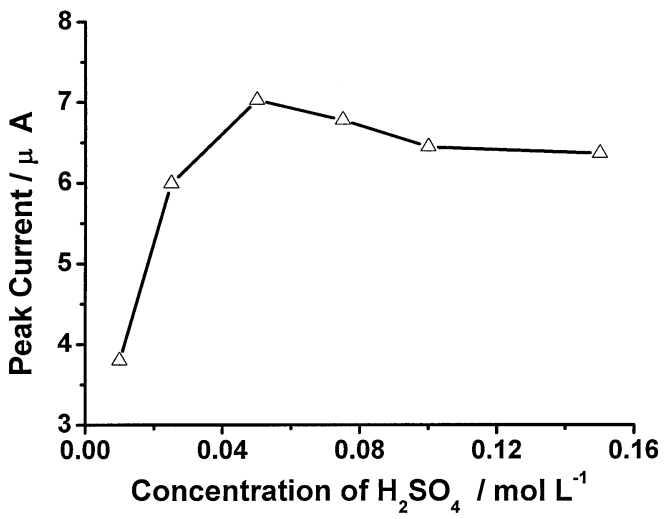

Fig. 4 Effect of the acidity on peak current of $5 \times 10^{-7} \mathrm{~mol} \mathrm{~L}^{-1}$ iodide. Other conditions: $0.1 \mathrm{~mol} \mathrm{~L}^{-1} \mathrm{NaCl}+1 \times 10^{-4} \mathrm{~mol} \mathrm{~L}^{-1}$ CTAB; accumulation potential, $1.0 \mathrm{~V}$; accumulation time, $60 \mathrm{~s}$; scan rate, $100 \mathrm{mV} \mathrm{s}^{-1}$.

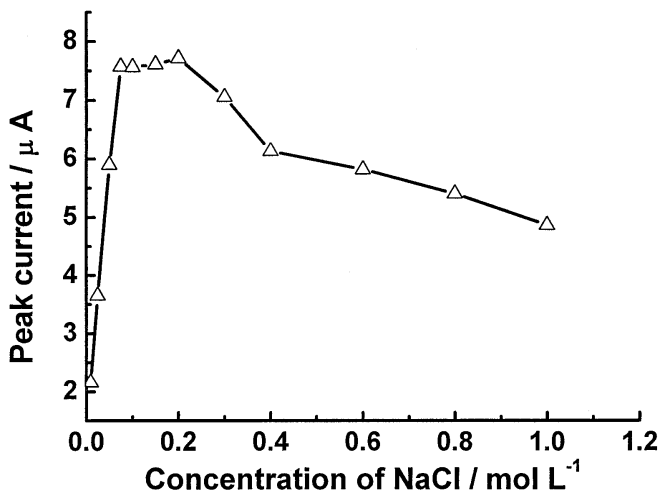

Fig. 5 Dependence of the peak current of $5 \times 10^{-7} \mathrm{~mol} \mathrm{~L}^{-1}$ iodide on the $\mathrm{Cl}^{-}$concentration. Other conditions: $0.05 \mathrm{~mol} \mathrm{~L}^{-1} \mathrm{H}_{2} \mathrm{SO}_{4}+1 \times$ $10^{-4} \mathrm{~mol} \mathrm{~L}^{-1} \mathrm{CTAB}$; accumulation potential, $1.0 \mathrm{~V}$; accumulation time, $60 \mathrm{~s}$; scan rate, $100 \mathrm{mV} \mathrm{s}^{-1}$.

$0.41 \mathrm{~V}$ to $0.38 \mathrm{~V}$, with further confirmed the formation of ionpairs. ${ }^{15}$

\section{Choice of supporting electrolyte}

The best results were obtained with acidic electrolyte, such as $\mathrm{HCl}$ and $\mathrm{H}_{2} \mathrm{SO}_{4}$. The acidity of the solution was adjusted with $\mathrm{H}_{2} \mathrm{SO}_{4}$; the effect of the concentration of $\mathrm{H}_{2} \mathrm{SO}_{4}$ on the peak current is shown in Fig. 4. The peak current increases with an increase of the acidity at first, and then reaches the maximum value corresponding to that of the concentration of $\mathrm{H}_{2} \mathrm{SO}_{4}$ at $0.05 \mathrm{~mol} \mathrm{~L}^{-1}$. $\mathrm{Cl}^{-}$was considered to form voluminous anions with iodine, which could further associate with CTAB, as $\mathrm{CTABI}_{2} \mathrm{Cl}$. Influence of the $\mathrm{NaCl}$ concentration on the peak current is illustrated in Fig. 5; the results show that when the chloride concentration was less than $1 \times 10^{-4} \mathrm{~mol} \mathrm{~L}^{-1}$, almost no evidential peak current was obtained, and thus the role of $\mathrm{Cl}^{-}$in the formation of ion-pairs was ascertained. The peak current increased with an increase in the chloride concentration until its concentration reached $0.1 \mathrm{~mol} \mathrm{~L}-1$. If a mixed solution of $\mathrm{H}_{2} \mathrm{SO}_{4}$ and $\mathrm{NaCl}$ was substituted by $0.1 \mathrm{~mol} \mathrm{~L}^{-1} \mathrm{HCl}$, the peak current showed no obvious change. Thus, $0.1 \mathrm{~mol} \mathrm{~L}^{-1} \mathrm{HCl}$ was selected as the supporting electrolyte. Figure 6 demonstrates that when the concentration of CTAB was less than $2.0 \times 10^{-6} \mathrm{~mol} \mathrm{~L}^{-1}$, there was found no peak current. However, the peak current increased linearly with the concentration of CTAB in the range 


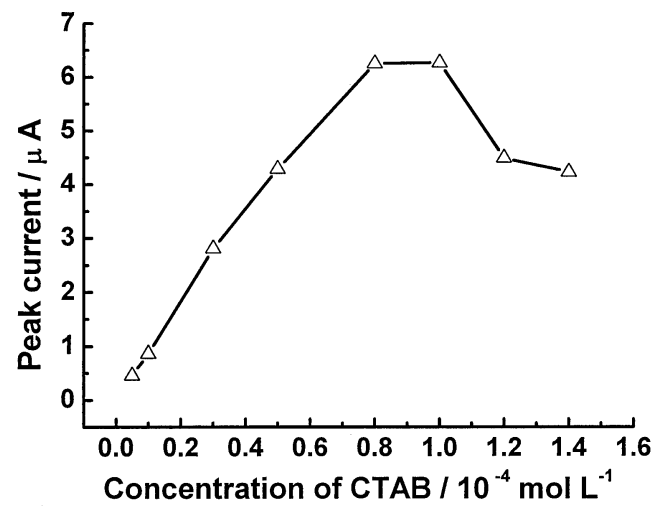

Fig. 6 Influence of the concentration of $\mathrm{CTAB}$ on the peak current of $5 \times 10^{-7} \mathrm{~mol} \mathrm{~L}^{-1}$ iodide. Other conditions: $0.1 \mathrm{~mol} \mathrm{~L}^{-1} \mathrm{HCl}$; accumulation potential, $1.0 \mathrm{~V}$; accumulation time, $60 \mathrm{~s}$; scan rate, 100 $\mathrm{mV} \mathrm{s}^{-1}$.

of $2.0 \times 10^{-6}-8.0 \times 10^{-5} \mathrm{~mol} \mathrm{~L}^{-1}$ until the maximum value was reached, and then began to decrease. It is presumed that CTAB, itself, might have adsorbed onto the carbon paste surface, and affected the deposition of $\mathrm{CTABI}_{2} \mathrm{Cl}$ when the concentration of CTAB was higher than $1 \times 10^{-4} \mathrm{~mol} \mathrm{~L}^{-1}$.

\section{Effect of the accumulation potential}

Based on cyclic voltammetric studies, a preferential peconcentration potential was selected within an interval from $0.7 \mathrm{~V}$ to $1.2 \mathrm{~V}$; it was observed that for a more positive potential being applied, the larger was the reduction current of iodine. While the applied potential was more than $1.1 \mathrm{~V}$, the recorded response became deformed and started to split. This was probably due to the formation of higher oxidation states of iodine and subsequent reactions. A value of $1.0 \mathrm{~V}$ was chosen as being the most suitable for accumulation.

\section{Effect of the accumulation time}

The effect of the accumulation time upon the peak current was studied. This effect is illustrated in Fig. 7 for two $\mathrm{I}^{-}$ concentrations, $5 \times 10^{-7} \mathrm{~mol} \mathrm{~L}^{-1}$ and $1 \times 10^{-6} \mathrm{~mol} \mathrm{~L}^{-1}$. The peak current increases linearly with the preconcentration time over the range of $10 \mathrm{~s}$ to $90 \mathrm{~s}$, and then tends to level off due to saturation of the carbon-paste surface for more highly concentrated iodine. A more diluted analyte solution required longer preconcentration time to reach saturation. As a consequence, the increase in the accumulation time in the goal to increase the sensitivity of detection would be effective only for a lower concentration of iodide; $60 \mathrm{~s}$ was selected as the accumulation time, because it can meet the requirement of sample detection.

\section{Effect of the scan rate on the peak current}

The effect of the scan rate on the peak current was also studied by varying the scan rate from $25 \mathrm{mV} \mathrm{s}^{-1}$ to $250 \mathrm{mV} \mathrm{s}^{-1}$. The peak current was found to be directly proportional to the scan rate, which indicated that the electrode processes were limited by adsorption. With an increase in the scan rate, the noise of the instrument also became louder. A scan rate of 100 $\mathrm{mV} \mathrm{s}^{-1}$ had a better signal-to-noise ratio under the conditions mentioned above.

\section{Reproducibility of the CPEs for the determination of iodide}

In general, owing to the strong affinity of carbon paste and ion-pairs, part of iodine may remain immobilized at the carbon-

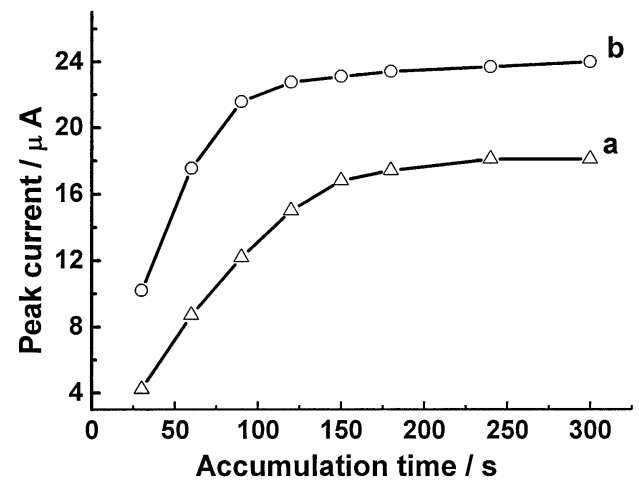

Fig. 7 Plots of the peak current versus accumulation time. (a) $5 \times$ $10^{-7}$ mol L ${ }^{-1}$ iodide (b) $1 \times 10^{-6} \mathrm{~mol} \mathrm{~L}^{-1}$ iodide; other conditions: 0.1 mol L ${ }^{-1} \mathrm{HCl}+1 \times 10^{-4} \mathrm{~mol} \mathrm{~L}^{-1} \mathrm{CTAB}$; accumulation potential, $1.0 \mathrm{~V}$; scan rate, $100 \mathrm{mV} \mathrm{s}^{-1}$.

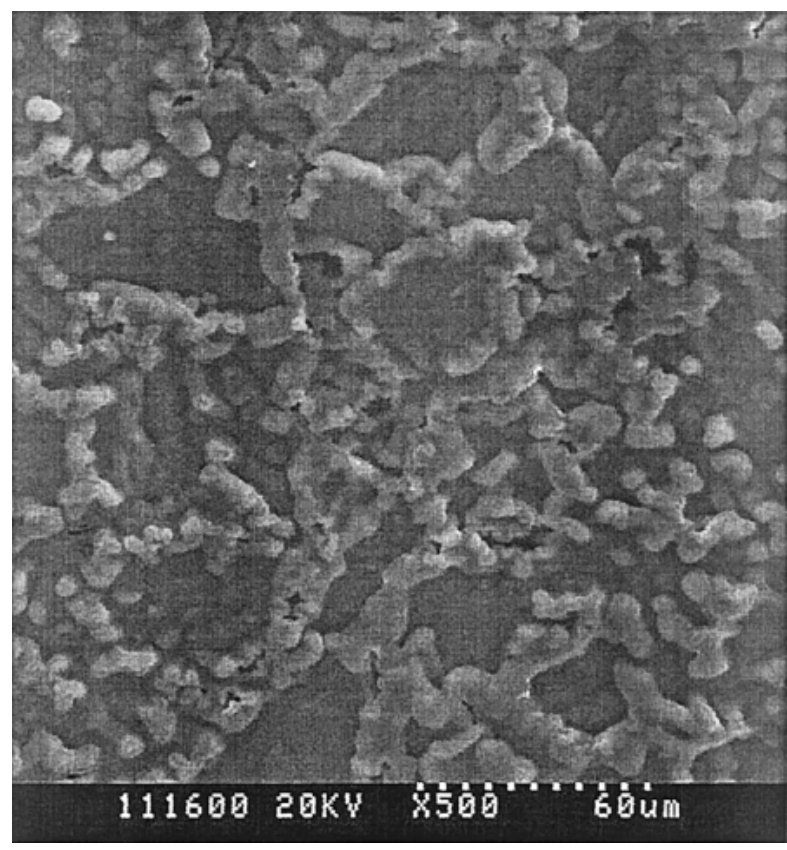

Fig. 8 SEM images of the carbon-paste electrode surface $(500 \times)$.

paste surface, and hence negatively influence all subsequent measurements. After accumulating in an iodide solution, the electrodes were rinsed with doubly distilled water, and repetitive potential scans from $0.7 \mathrm{~V}$ to $0.1 \mathrm{~V}$ were carried out in a blank solution. After ten successive potential scans, there was still a small reduction peak which appeared at $0.38 \mathrm{~V}$. Accordingly, an undesirable "memory effect" must be eliminated by mechanical removing the outer layer of the carbon paste after each scan. However, this manual operation may change the electrode surface conditions, and thus the reproducibility of the measurements can be somewhat deteriorated. As can be seen from Fig. 8, the SEM image of the CPE surface shows that a homogeneous carbon-paste electrode surface can be obtained by this method, and that a good reproducibility is expected. In this study, the reproducibility of the CPEs was examined using a model solution containing $5 \times$ $10^{-7} \mathrm{~mol} \mathrm{~L}^{-1}$ iodide in $0.1 \mathrm{~mol} \mathrm{~L}^{-1} \mathrm{HCl}$. In 10 replicates, the response of iodine at renewed electrode surfaces could be reproduced with a relative standard deviation of $3.4 \%$. This 

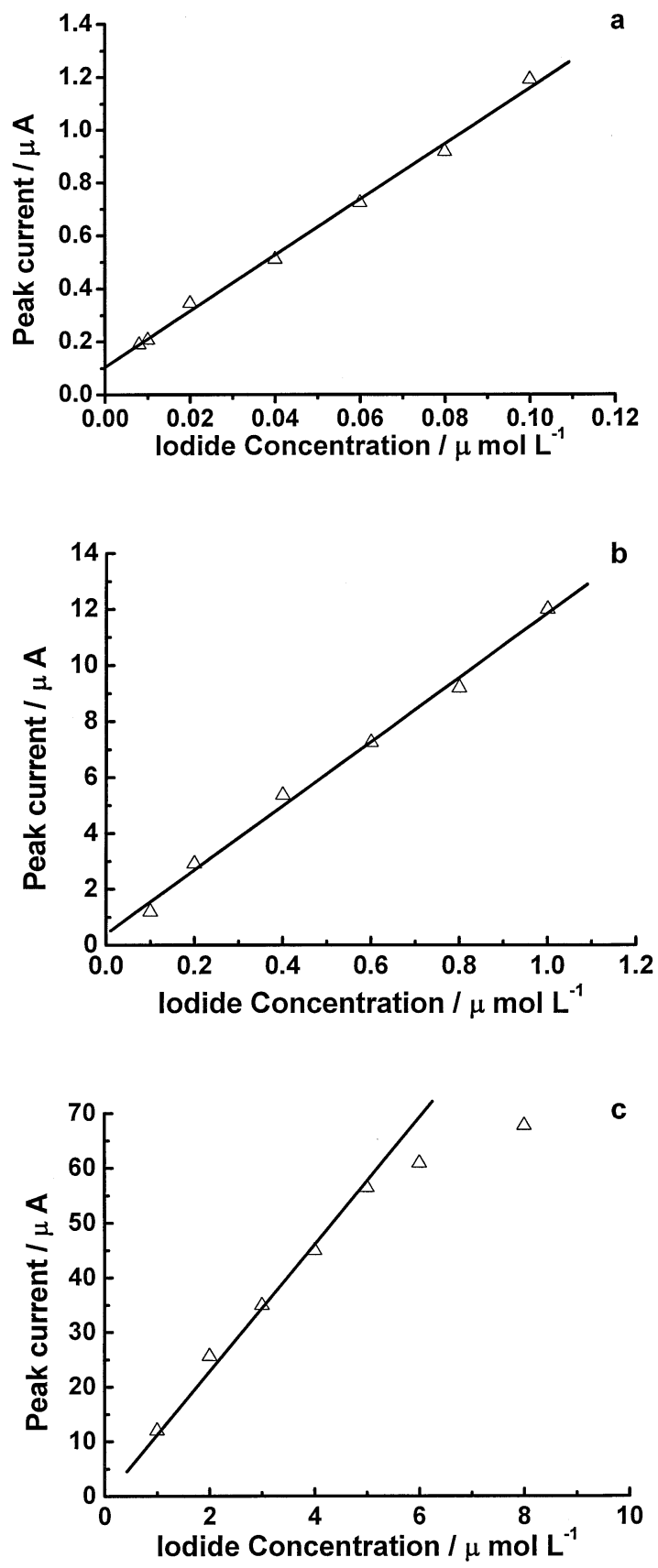

Fig. 9 Calibration plots for iodide determination were shown for three concentration range: $0.8 \times 10^{-8} \mathrm{~mol} \mathrm{~L}^{-1}$ to $10 \times 10^{-8} \mathrm{~mol} \mathrm{~L}^{-1}$ (a), $1.0 \times 10^{-7} \mathrm{~mol} \mathrm{~L}^{-1}$ to $10 \times 10^{-6} \mathrm{~mol} \mathrm{~L}^{-1}$ (b), $1.0 \times 10^{-6} \mathrm{~mol} \mathrm{~L}^{-1}$ to $8 \times$ $10^{-6} \mathrm{~mol} \mathrm{~L}^{-1}$ (c). Conditions: $0.1 \mathrm{~mol} \mathrm{~L}-1 \mathrm{HCl}+1 \times 10^{-4} \mathrm{~mol} \mathrm{~L}^{-1}$ CTAB; accumulation potential, $1.0 \mathrm{~V}$; accumulation time, $60 \mathrm{~s}$; scan rate, $100 \mathrm{mV} \mathrm{s}^{-1}$.

result indicated that the CPEs fabricated by this method have good precision for the determination of iodide.

Calibration curves and detection limit for the determination of iodide

By applying the optimal conditions described above, the dependence of the peak current and the concentration of iodide was examined (Fig. 9). The peak current was proportionate to the iodide concentration over a wide range from $8 \times 10^{-9} \mathrm{~mol}$ $\mathrm{L}^{-1}$ to $5 \times 10^{-6} \mathrm{~mol} \mathrm{~L}^{-1}$. When the concentration was higher than $5 \times 10^{-6} \mathrm{~mol} \mathrm{~L}^{-1}$, the peak currents increased slightly with improving the concentration, and tended to a constant, which
Table 1 Effect of interferential ions on the peak current of $5 \times$ $10^{-7} \mathrm{~mol} \mathrm{~L}^{-1}$ iodide

\begin{tabular}{|c|c|c|c|}
\hline & Interferent & Concentration $/ \mathrm{mol} \mathrm{L}^{-1}$ & Signal change, $\%$ \\
\hline $\mathrm{SO}_{3}^{2-}$ & & $2 \times 10^{-4}$ & 1.05 \\
\hline $\mathrm{CO}_{3}{ }^{2-}$ & & $5 \times 10^{-3}$ & -0.680 \\
\hline $\mathrm{NO}_{3}^{-}$ & & $2 \times 10^{-4}$ & -3.6 \\
\hline $\mathrm{NO}_{2}^{-}$ & & $2 \times 10^{-5}$ & 5.3 \\
\hline $\mathrm{SCN}^{-}$ & & $2 \times 10^{-6}$ & -23.2 \\
\hline $\mathrm{Br}^{-}$ & & $5 \times 10^{-4}$ & +2.7 \\
\hline $\mathrm{ClO}_{4}^{-}$ & & $1 \times 10^{-4}$ & -0.950 \\
\hline $\mathrm{C}_{2} \mathrm{O}_{4}^{2-}$ & & $1 \times 10^{-5}$ & -0.09 \\
\hline \multirow[t]{2}{*}{$\mathrm{Pb}^{2+}$} & (not added EDTA) & $1 \times 10^{-6}$ & Peak vanish \\
\hline & (added EDTA) & $5 \times 10^{-6}$ & -3.56 \\
\hline \multirow[t]{2}{*}{$\mathrm{Cu}^{2+}$} & (not added EDTA) & $1 \times 10^{-6}$ & Peak vanish \\
\hline & (added EDTA) & $5 \times 10^{-6}$ & -4.98 \\
\hline
\end{tabular}

EDTA (ethylene diamine tetraacetic acid): $1 \times 10^{-4} \mathrm{~mol} \mathrm{~L}^{-1}$.

suggests that the adsorption of ion-pairs occurred at the carbonpaste electrode began to reach saturation. The detection limit (3:1 signal-to-noise ratio) for the determination of iodide with CPEs was estimated to be $2 \times 10^{-9} \mathrm{~mol} \mathrm{~L}^{-1}$ when using accumulation for $3 \mathrm{~min}$.

\section{Interferences}

The influence of various possible interfering ions, such as $\mathrm{Br}^{-}$, $\mathrm{SO}_{3}{ }^{2-}, \mathrm{SCN}^{-}, \mathrm{CO}_{3}{ }^{2-}, \mathrm{NO}_{2}{ }^{-}, \mathrm{NO}_{3}{ }^{-}, \mathrm{ClO}_{4}{ }^{-}, \mathrm{C}_{2} \mathrm{O}_{4}{ }^{2-}, \mathrm{Pb}^{2+}$ and $\mathrm{Cu}^{2+}$, was evaluated, and the results are listed in Table 1. Only $\mathrm{SCN}^{-}$, $\mathrm{Pb}^{2+}$, and $\mathrm{Cu}^{2+}$ obviously affected the determination of $\mathrm{I}^{-}$. Fortunately, the concentration of $\mathrm{SCN}^{-}$was lower than the concentration of $\mathrm{I}^{-}$in most samples, and when the cocentration of $\mathrm{SCN}^{-}$was relatively lower, $\mathrm{SCN}^{-}$adsorbed on the electrode surface could be oxidized to convert into $\mathrm{SO}_{3}{ }^{2-}$ when a positive potential was applied during the accumulation process, and thus the effect was eliminated. The interference of $\mathrm{Pb}^{2+}$ and $\mathrm{Cu}^{2+}$ could be eliminated by adding $1 \times 10^{-4} \mathrm{~mol} \mathrm{~L}^{-1}$ of ethylene diamine tetraacetic acid (EDTA), since EDTA does not interfere with the determination of iodide.

\section{Sample analysis}

Since table salt is an important source by which people incept iodine in China, the determination of iodide in table salt is significant. Table-salt samples were analyzed by the standard addition method. Since real samples are soluble in water, the sample treatment of table salt was very simple. The results for the determination of iodine in samples are summarized in Table 2. The results were in good agreement with the reference values obtained by UV spectrophotometry. The recovery percentages were 98.6-102.4\%, which shows the good accuracy of this procedure. Additionally, the measuring time of this method is relatively short (about $15 \mathrm{~min}$ ).

\section{Conclusion}

The method investigated here for the determination of iodide with carbon-paste electrodes in the presence of CTAB is simple and sensitive, requiring only a short analysis time, and employing inexpensive, easily prepared working electrodes. We have highlighted here our interest in the synergistic accumulation of iodine with CTAB at carbon-paste electrodes in acidic chloride electrolyte. Quaternary ammonium salt CTAB has been used as an ionic associating agent to accumulate $\mathrm{I}_{2} \mathrm{Cl}^{-}$, which was produced by oxidizing and then being adsorbed on 
Table 2 Results of determination of iodide in table salts and the recoveries

\begin{tabular}{|c|c|c|c|c|c|c|c|}
\hline Sample No. & Original $^{\mathrm{a}} / \mu \mathrm{g} \mathrm{g}^{-1}$ & Added $/ \mu \mathrm{M}$ & Expected $/ \mu \mathrm{M}$ & Found $/ \mu \mathrm{M}$ & RSD, \% & Recovery, \% & UV spectrophotometry/ $\mu \mathrm{g} \mathrm{g}^{-1}$ \\
\hline 1 & 30.47 & - & - & 0.575 & 3.2 & - & 29.87 \\
\hline 1 & & 0.5 & 1.075 & 1.101 & 3.9 & 102.4 & \\
\hline 2 & 28.56 & - & - & 0.539 & 4.1 & - & 27.63 \\
\hline 2 & & 1.0 & 1.539 & 1.517 & 3.7 & 98.6 & \\
\hline 3 & 32.37 & - & - & 0.611 & 3.8 & - & 32.19 \\
\hline 3 & & 1.5 & 2.111 & 2.107 & 4.4 & 99.8 & \\
\hline
\end{tabular}

a. Original value is obtained by multiplying the detected value by the dilution factor of 1000 .

the working electrode. The optimum conditions for the analysis of iodide were as follows: $0.1 \mathrm{~mol} \mathrm{~L}^{-1} \mathrm{HCl}$ as the supporting electrolyte; CTAB concentration of $1 \times 10^{-4} \mathrm{~mol} \mathrm{~L}^{-1} ; 1.0 \mathrm{~V}$ as the accumulation potential and an accumulation time of $60 \mathrm{~s}$; and a scan rate of $100 \mathrm{mV} \mathrm{s}^{-1}$. Under the optimum conditions, the peak current was linearly related to the concentration of iodide in the range of $8 \times 10^{-9}-5 \times 10^{-6} \mathrm{~mol} \mathrm{~L}^{-1}$. The detection limit was $2 \times 10^{-9} \mathrm{~mol} \mathrm{~L}^{-1}$ after $3 \mathrm{~min}$ of accumulation. This procedure is suitable for the determination of iodide in table-salt samples.

\section{Acknowledgements}

This research was supported by the National Natural Science Foundation of China (No. 60171023), the Natural Science Foundation of Hubei Province (No. 99J060) and the Science Fundation of Qujing Normal College (0113904).

\section{References}

1. J. L. Lambert, G. L. Hatch, and B. Mosier, Anal. Chem., 1975, 47, 915.

2. C. Reifenhauser and K. G. Heumann, Fresenius J. Anal. Chem., 1990, 336, 559.
3. H. S. Shin, Y. S. Oh-Shin, J. H. Kim, and J. K. Ryu, J. Chromatogr. A, 1996, 732, 327.

4. E. H. Larsen and M. B. Ludwigsen, J. Anal. At. Spectrom., 1997, 12, 435.

5. Y. Bichsel and U. von Gunten, Anal. Chem., 1999, 71, 34.

6. X. Hou, H. Dahlgaard, B. Rietz, U. Jacobsen, S. P. Nielsen, and A. Aarkrog, Anal. Chem., 1999, 71, 2745.

7. W. Holak, Anal. Chem., 1987, 59, 2218.

8. B. Fang, S. P. Li, H. Q. Fang, and H. Y. Cheng, Fenxihuaxue, 1997, 25, 59.

9. R. F. Lane and A. T. Hubbard, J. Phys. Chem., 1975, 79, 808.

10. S. X. Yang, S. J. Fu, and M. L. Wang, Anal. Chem., 1991, 63, 2970.

11. G. H. Lu, Y. Min, Q. F. Zhang, A. L. Wang, and Z. X. Jin, Electroanalysis, 1995, 7, 591.

12. M. K. Kwak, D. S. Park, M. S. Won, and Y. B. Shim, Electroanalysis, 1996, 8, 680.

13. J. S. Yeom, M. S. Won, and Y. B. Shim, J. Electroanal. Chem., 1999, 463, 16.

14. A. Walcarius, G. Lefevre, J. P. Rapin, G. Renaudin, and M. Francois, Electroanalysis, 2001, 13, 313.

15. I. S̆vancara, J. Konvalina, K. Schachl, K. Kalcher, and K. Vytřas, Electroanalysis, 1998, 10, 435.

16. K. Vytras and J. Konvalina, Electroanalysis, 1998, 10, 787.

17. G. Farsang, Acta Chim. Hung., 1965, 45, 163. 